\title{
The role of percutaneous endoscopic gastrostomy in spinal cord injured patients
}

\author{
RA Frost ${ }^{1}$, H Rivers $^{2}$, AM Tromans ${ }^{3}$ and DJ Grundy ${ }^{3}$ \\ ${ }^{1}$ Consultant Radiologist, ${ }^{2}$ Head of Service Dietetics, ${ }^{3}$ Consultant in Spinal Injuries, Salisbury District Hospital, \\ Salisbury SP2 8BJ, UK
}

Our experience with percutaneous endoscopic gastrostomy (PEG) in spinal cord injured patients is described. We have shown it to be a safe, comfortable and easily managed method of providing an adequate nutritional and fluid intake in patients requiring long-term tube feeding. It avoids the risks of intravenous feeding and the serious complications of oesophageal ulceration and stricture, which may occur with prolonged nasogastric intubation.

Keywords: percutaneous endoscopic gastrostomy; spinal cord injury

\section{Introduction}

Percutaneous endoscopic gastrostomy (PEG) was first described in 1980 as a method of obtaining access to the stomach in patients requiring long-term tube feeding. ${ }^{1}$ It has proved to be a safe technique, and avoids the discomfort and complications of prolonged nasogastric intubation or intravenous feeding.

In a recent series of 41 patients undergoing PEG by one of the authors (RAF), 32 had a neurological disorder of swallowing, the commonest causes being hemiplegia and head injury, but there were no patients with spinal cord injury. ${ }^{2}$

Although the use of surgical feeding tubes ${ }^{3}$ and radiological percutaneous gastrostomy placement ${ }^{4}$ has been recently described in spinal cord injured patients, the use of the PEG technique in this group of patients has not been previously reported.

\section{Patients}

Over the past $3 \frac{1}{2}$ years, eleven patients with spinal cord injury have been fed by gastrostomy performed at this centre using the PEG technique. Nine of these patients were acutely injured and represented $5 \%$ of all new acute admissions during this period. One patient (patient 3), who had severe rheumatoid arthritis, developed a spontaneous $\mathrm{C} 1-2$ subluxation with tetraplegia. The other patient (patient 6) had developed gram negative septicaemia following percutaneous nephrolithotomy and required prolonged intensive care. Ten patients had a tracheostomy and six were ventilated.

A further five patients who do not form part of this study were admitted to this centre with a gastrostomy already in place. They mostly had neurological feeding problems eg Guillain-Barré syndrome, Parkinson's disease with spinal cord injury. One patient had sustained a gunshot wound to the stomach and spine.
Description of the technique

1 The patient is sedated intravenously while lying supine, and the gastroscope is passed down the oesophagus into the stomach.

2 The stomach is then inflated with air, and the tip of the gastroscope is directed anteriorly to transilluminate the abdominal wall to ensure that there is no small or large bowel lying between the stomach and the anterior abdominal wall.

3 A cannula is inserted percutaneously via the anterior abdominal wall into the inflated stomach. Local anaesthetic is rarely necessary in the spinal cord injured patient.

4 A long thread is passed through the cannula, and grasped with biopsy forceps. The gastroscope, biopsy forceps and thread are then withdrawn through the mouth.

5 The thread is tied to the tapered end of the gastrostomy tube. The tube is then pulled down the oesophagus, into the stomach, and out through the anterior abdominal wall. The flange on the inner end of the gastrostomy tube maintains the end of the tube within the gastric lumen.

In this series, the 15 French gauge FRENTA PEG set (Fresenius, Cheshire, UK) was used. Feeding via the PEG is normally commenced after $12 \mathrm{~h}$.

\section{Important aspects of the PEG technique in spinal cord} injured patients

There must be the facility to ventilate quickly, in case sedation of the patient causes a ventilatory problem. To date this has never been necessary. Most patients are already ventilated and have a tracheostomy. The cuff of the tracheostomy tube must be inflated.

The entire examination is performed with the patient in the supine position. This has not been found to be a disadvantage. The flexed lateral position, which is 
normally used for intubation of non-spinal injured patients would be dangerous and totally inappropriate in acutely injured spinal patients.

As there is sometimes a tendency to aspirate, even with a correctly positioned gastrostomy tube because the patient is supine, a jejunal tube can be inserted through the feeding gastrostomy and positioned in the jejunum, until the patient is able to sit up. This was necessary in only two patients.

Although in non-spinal patients, the PEG insertion is normally carried out in the radiology department, we have almost always performed the procedure in spinai patients on the ward, largely because of the fact that the patient is often ventilated. We found it so convenient, that it is now our routine practice. The patient's bed space needs to be darkened in order to see the tip of the illuminated gastroscope through the abdominal wall.

Feeding via the PEG is normally commenced after twelve hours with water, and then gradually built up over about 3 days. A variety of different complete feeds have been used, depending on requirements, the daily energy intake achieved being in the range of 1400 to $2400 \mathrm{kcal}$. As patients have been increasingly able to manage an oral intake, PEG feeding has been adjusted to provide supplementary feeding, often consisting of 1000 to $1500 \mathrm{kcal}$ at night.

When patients are able to manage a full diet by mouth, feeding via the PEG is stopped, but the gastrostomy is left in situ for 2-4 weeks, to ensure that food intake and weight are maintained, before removal.

\section{Results}

Details of the patients, with timing and duration of gastrostomy feeding, are shown in Table 1.

Nine of the eleven patients resumed normal oral feeding.

Two patients died, but the cause of death was unrelated to the gastrostomy.
Patient 3, who had severe rheumatoid arthritis, had developed a spontaneous $\mathrm{C} 1-2$ subluxation and was on long-term ventilation, developed septic arthritis in a severely diseased knee, and rapidly deteriorated with septicaemia.

Patient 5 developed an oesophageal stricture due to nasogastric feeding, but in spite of the gastrostomy and repeated oesophageal dilatations, the stricture remained very tight and she died of aspiration pneumonia.

\section{Discussion}

\section{Indications}

From our experience with the PEG technique, we regard the indications for its use as follows: (1) recurrent aspiration with the risk of aspiration pneumonia; (2) oesophageal stricture or dysphagia; (3) patients likely to have a long-term feeding problem; (4) patients with a high cervical cord injury who have a swallowing difficulty and who are also likely to require a tracheostomy and assisted ventilation.

\section{Complications}

There were no serious complications. The gastrostomy tube occasionally became blocked and required flushing out with water. Patient 1 aspirated gastric contents when fed through the gastrostomy tube, and required a jejunal tube, which was inserted by the radiologist through the PEG tube. Patient 8 also had a jejunal tube, because of poor absorption during enteral feeding.

Although the site of insertion of the PEG should be checked each day for inflammation, this was never encountered.

\section{Advantages}

The PEG is easier to manage than a nasogastric tube. It is wider, and less likely to block. Unlike a nasogastric

Table 1 Timing and duration of gastrostomy feeding

\begin{tabular}{lcccc}
$\begin{array}{l}\text { Patient } \\
\text { number }\end{array}$ & $\begin{array}{c}\text { Neurological } \\
\text { level of } \\
\text { injury }\end{array}$ & $\begin{array}{c}\text { Time after injury } \\
\text { PEG sited } \\
\text { (weeks) }\end{array}$ & $\begin{array}{c}\text { PEG } \\
\text { feeding } \\
\text { (weeks) }\end{array}$ & $\begin{array}{c}\text { Total time PEG } \\
\text { in situ } \\
\text { (weeks) }\end{array}$ \\
\hline 1 & C6 & 13 & 10 & 12 \\
2 & T6 & 8 & 15 & 17 \\
3 & C3 & 9 & 13 & 13 (died) \\
4 & C6 & 4 & 5 & 7 (died) \\
5 & L1 & 14 & 7 & 7 \\
6 & C7 & Not & 4 & 17 \\
7 & applicable & 12 & 23 \\
8 & C7 & 6 & 17 & 33 \\
9 & C2 & 4 & 19 & 27 \\
10 & C2 & 5 & 21 & 7 \\
11 & C5 & 2 & 3 & 15.6 \\
Median time (weeks) & T9 & 7 & 11.5 & \\
\hline
\end{tabular}


tube, the PEG does not require to be repositioned. The use of X-rays is unnecessary to check the position.

The PEG is more comfortable for the patient and, unlike a nasogastric tube, is not in the direct line of vision. It is easier for patients to swallow, particularly if they have a tracheostomy. It avoids the serious complications of nasogastric tubes-oesophageal ulceration and stricture formation.

The PEG is more discreet than a nasogastric tube, and allows more independence and mobility. Patients with lower spinal cord lesions are able to feed themselves through the PEG. It is a more flexible method of feeding and allows an adequate diet to be established, before it is removed.

One of the authors (RAF) has placed more than 400 gastrostomies, including the eleven in spinal cord injured patients described above. Although percutaneous placement of gastrostomies under radiological control $^{4}$ has also been performed, we prefer the PEG technique, believing (1) that it more reliably avoids damage to structures lying between the skin and the stomach; and (2) that it allows the gastrostomy tube to be pulled rather than pushed through the gastric wall, thereby avoiding potential damage to posterior structures.
Oesophageal strictures do not preclude PEG placement as the stricture can be dilated endoscopically prior to gastrostomy.

\section{Conclusion}

We have found that the PEG technique is a safe, comfortable and easily managed method of providing an adequate nutritional and fluid intake in spinal cord injured patients. In addition, it avoids the serious complications of oesophageal ulceration and stricture which may occur with prolonged nasogastric intubation.

\section{References}

1 Gauderer MWL, Ponsky JL, Izant RJ. Gastrostomy without laparotomy: a percutaneous endoscopic technique for feeding gastrostomy. J Pediatr Surg 1980; 15: 872-875.

2 Moran BJ, Frost RA. Percutaneous endoscopic gastrostomy in 41 patients: indications and clinical outcome. J $R$ Soc Med 1992; 85: 320-321.

3 Frost F, Rosen B, Begley J, Lee SB. Judicious use of surgical feeding tubes in SCI acute care. J Am Paraplegia Soc 1994; 17: 121.

4 Bodley R, Banerjee S. Radiological percutaneous gastrostomy placement for enteral feeding. Paraplegia 1995; 33: 153-155. 